\title{
Efeito da fonte protéica e do processamento físico do concentrado sobre a terminação de bovinos jovens confinados e o impacto ambiental dos dejetos
}

\author{
Glauco Mora Ribeiro ${ }^{1}$, Alexandre Amstalden Moraes Sampaio ${ }^{2}$, Alexandre Rodrigo Mendes \\ Fernandes $^{1}$, Wignez Henrique ${ }^{3}$, Atushi Sugohara ${ }^{4}$, Ana Carolina Amorim ${ }^{1}$
}

\footnotetext{
${ }^{1}$ Doutorando pela FCAV/UNESP, Jaboticabal, SP.

2 Depto. Zootecnia/FCAVIUNESP, Jaboticabal, SP. Bolsista CNPq.

3 UPD/Apta Regional/SAA, São José do Rio Preto, SP.
}

${ }^{4}$ Depto. Zootecnia/FCAV/UNESP, Jaboticabal, SP.

\begin{abstract}
RESUMO - O objetivo nesta pesquisa foi avaliar o efeito de dois ingredientes protéicos da dieta (farelo de soja e de algodão) e de dois processamentos físicos do concentrado (farelado e extrusado) na terminação de 16 bovinos machos não-castrados da raça Canchim. Avaliaram-se ainda a excreção de nutrientes nos dejetos e o potencial de produção de biogás. Os animais tinham 12 meses de idade e $315 \mathrm{~kg}$ PC, em média, e foram confinados em baias individuais durante 147 dias (os primeiros 35 dias foram de adaptação). Como volumoso utilizou-se silagem de milho, em uma relação volumoso:concentrado de 50:50, com base na MS Os resultados foram analisados em delineamento inteiramente casualizado, em esquema fatorial $2 \times 2$ (fonte protéica $\times$ processamento físico). A fonte protéica influenciou o ganho de peso corporal (1,50 e 1,35 kg/dia para o farelo de soja e de algodão, respectivamente), a conversão alimentar (4,73 e 5,31 kg MS ingerida/kg de ganho de peso, respectivamente) e a eficiência protéica (1,78 e 1,59 kg de ganho de peso/kg PB ingerida, respectivamente). O tratamento físico do concentrado e a fonte protéica não influenciaram a ingestão de MS, a área de olho-de-lombo e a espessura de gordura, estimadas por ultra-som. O balanço de nutrientes foi semelhante entre tratamentos para MS, FDN e FDA, mas a fonte protéica determinou diferenças no balanço de PB. Entre os macro e microminerais quantificados nas fezes, os teores de P e Mg diferiram entre as fontes protéicas e a extrusão aumentou o conteúdo de Ca, com médias de 0,39 e 0,43 g/100 g de MS de dejetos, respectivamente, para os concentrados farelado e extrusado. Os dejetos produziram biogás de maneira efetiva entre o $70^{0}$ e o $200^{\circ}$ dia.
\end{abstract}

Palavras-chave: biodigestão, extrusão, farelo de algodão, farelo de soja, minerais, fezes

\section{Effect of the protein source and physical processing of the concentrate on the finishing of feedlot young bulls and environmental impact of dejections}

\begin{abstract}
The objective of this research was to evaluate the effect of two protein ingredients of the diet (soybean and cottonseed meals) and two physical process of the concentrate (grounded and extruded) upon the finishing of 16 Canchim young bulls. It was evaluated also the nutrients excretion in feces and biogas production potential. The animals were 12 monthyear-old, with initial $315 \mathrm{~kg} \mathrm{BW}$, and they were confined in individual pens for 147 days, being the first 35 days of adaptation. The roughage used was corn silage and the forage:concentrate rate was 50:50, on dry matter basis. The results were analyzed in a total randomized design, in a $2 \times 2$ factorial arrangement (protein source $\mathrm{x}$ physical process). There was effect of protein source upon the body weight gain (1.50 and $1.35 \mathrm{~kg}$ /day with soybean and cottonseed meal, respectively), feed conversion (4.73 and $5.31 \mathrm{~kg} \mathrm{DM} \mathrm{intake/kg} \mathrm{weight} \mathrm{gain,} \mathrm{respectively)} \mathrm{and} \mathrm{protein} \mathrm{efficiency} \mathrm{(1.78} \mathrm{and} 1.59 \mathrm{~kg}$ weight gain/kg CP intake, respectively). There was no difference among treatments for DM, loin eye area and subcutaneous fat thickness, evaluated by ultra-sound. The nutrient balance was similar among treatments for DM, NDF and ADF, but protein source caused differences in $\mathrm{CP}$ balance. Among the macro and microminerals determined in feces, $\mathrm{P}$ and $\mathrm{Mg}$ contents were different among protein sources, and extrusion increased Ca content, with means of 0.39 and $0.43 \mathrm{~g} / 100 \mathrm{~g}$ dejections dry matter, respectively for grounded and extruded concentrate. The dejections produced biogas effectively from $70^{\text {th }}$ to $200^{\text {th }}$ days.
\end{abstract}

Key Words: biogas, cottonseed meal, extrusion, feces, mineral, soybean meal

\section{Introdução}

A alimentação constitui-se um dos principais custos do confinamento, sendo a fração protéica a mais onerosa por unidade, o que estimula o estudo de diferentes fontes protéicas, pois estas podem proporcionar desempenhos e custos diferentes. Outro fator que pode alterar o aproveitamento da proteína é a utilização de tratamentos físicos e químicos, como extrusão e peletização, foco de pesquisas visando aumentar a eficiência da utilização 
dos alimentos e melhorar o aproveitamento do potencial dos animais.

Segundo O’Connor (1987), a extrusão é um processo de cozimento à alta pressão, umidade e temperatura em curto espaço de tempo. Esse processo causa gelatinização e expansão dos grânulos de amido (Haythornthwaite, 1986), além de alterar as estruturas terciária e quaternária da proteína (Camire, 1991).

A preocupação com a degradação ambiental das atividades produtivas tem sido crescente e os resíduos, que, no caso do confinamento de animais são os dejetos, camas e restos de alimentação, são geralmente utilizados ou depositados indevidamente. Além da limitação de espaço físico para a deposição desses resíduos, ocorre aumento das emissões de gás carbônico $\left(\mathrm{CO}_{2}\right)$ e metano $\left(\mathrm{CH}_{4}\right)$, eutrofização das fontes de água e poluição do solo (GüngörDemirci \& Demirer, 2004). O impacto pode ser agravado, pois parte do nitrogênio orgânico pode se perder por volatilização na forma de amônia $\left(\mathrm{NH}_{3}\right)$ ou se transformar em nitrato $\left(\mathrm{NO}_{3}\right)$ por ação dos microrganismos (Kelleher et al., 2002). Além disso, os micronutrientes nos dejetos podem causar problemas de fitotoxicidade no solo, ou ainda, ao percolarem ou serem levadas pela água da chuva, contaminam as reservas hídricas (Nicholson et al., 1999).

De acordo com Teixeira (2004), o fornecimento de dietas que atendam às exigências nutricionais dos animais pode evitar prejuízos econômicos e ambientais, pois reduz o desperdício de nutrientes e minimiza a deposição de poluentes no ambiente. Além de diferentes nutrientes, o tratamento físico ou químico da ração também afeta o impacto ambiental da atividade.

Segundo estimativa do Anualpec (2003), em 2012, o rebanho bovino do estado de São Paulo contará com 11.463.793 animais; considerando a produção de 0,02 a 0,03 t de $\mathrm{CH}_{4}$ /animal, estimada por Minami \& Tanaka (1997), pode-se calcular uma produção de mais de 300 mil toneladas de $\mathrm{CH}_{4}$ produzidas com a fermentação dos dejetos de bovinos, somente no estado de São Paulo.

A extensão do impacto causado pode ser minimizada com a utilização de sistemas de reciclagem de nutrientes dos dejetos. Um desses sistemas é a biodigestão anaeróbia, que é eficiente, pois, além de gerar o biofertilizante e produzir o biogás, fonte de energia alternativa, estabiliza a matéria orgânica e reduz ou elimina os coliformes (Al-Masri, 2001). A produção de biogás resultante da fermentação de $1 \mathrm{~kg}$ de esterco bovino é de 0,036 a $0,042 \mathrm{~m}^{3}$, suficiente para atender à demanda de biogás diária por habitante da zona rural, de 0,023 a 0,043 $\mathrm{m}^{3}$ (Ramachandra et al., 2004).

De acordo com Caeeb (1981), a aplicação de biofertilizante no solo, resultante da produção de biogás, apresenta inúmeras vantagens: melhoria na estrutura do solo, maior capacidade de retenção de água, introdução de grande número de bactérias e protozoários e introdução de alguns minerais importantes para o crescimento das plantas, entre outras.

Este trabalho foi realizado com o objetivo de avaliar o efeito de duas fontes protéicas (farelo de soja e de algodão) e de dois tratamentos físicos do concentrado (farelado e extrusado) sobre o desempenho de bovinos jovens da raça Canchim em confinamento, o balanço de nutrientes e o impacto ambiental dos dejetos, medido por meio da quantificação de minerais e do potencial de produção de biogás.

\section{Material e Métodos}

O experimento foi conduzido nas dependências da Faculdade de Ciências Agrárias e Veterinárias/Unesp, Campus de Jaboticabal, localizada na região norte do estado de São Paulo, geograficamente definida pelas coordenadas de $21^{\circ} 15^{\prime} 22^{\prime \prime}$ de latitude Sul e $48^{\circ} 18^{\prime} 58 "$ de longitude Oeste. A altitude local é de 595 m e o clima, segundo classificação de Köppen, é do tipo subtropical, com chuvas de verão e inverno relativamente seco. A precipitação pluviométrica anual é de $1.415 \mathrm{~mm}$ e a umidade relativa do ar de 70,8\%, segundo dados da estação agroclimatológica.

Foram utilizados 16 bovinos não-castrados da raça Canchim, com 12 meses de idade e peso corporal médio inicial de $315 \mathrm{~kg}$, distribuídos aleatoriamente nos tratamentos. Os animais foram alojados em baias individuais de piso concretado, com área de $16 \mathrm{~m}^{2} /$ baia, contendo $4 \mathrm{~m}$ de cocho coberto. Após período de adaptação de 35 dias, iniciou-se o período experimental, que teve duração de 112 dias.

Foram avaliadas quatro dietas experimentais, formuladas para serem isoprotéicas e isoenergéticas, mantendo-se sempre relação volumoso:concentrado de 50:50 e variando-se a fonte protéica (farelo de soja ou de algodão) e o tratamento físico do concentrado (farelado ou extrusado). As dietas (Tabela 1) foram ajustadas para ganho de peso corporal de 1,4 kg/dia, com auxílio do programa RLM ${ }^{\circledR}$ (Lanna et al., 1999).

Todos os concentrados foram processados em moinho de martelos, provido de peneira com crivos de 2,8 $\mathrm{mm}$. Os concentrados extrusados foram passados ainda em outro moinho com peneira com crivos de $0,8 \mathrm{~mm}$. Posteriormente, foram processados em extrusora de rosca simples, provida de gerador de vapor. O equipamento era constituído de condicionador com pás condutoras e homogeneizadoras dos ingredientes e sistema para umidificar a mistura, de modo que a massa atingisse teor de umidade de aproxima- 
Tabela 1 - Proporção de ingredientes e composição bromatológica das dietas experimentais Table 1 - Proportion of ingredients and bromatological composition of experimental diets

\begin{tabular}{|c|c|c|c|c|}
\hline \multirow[t]{2}{*}{ Item } & \multicolumn{4}{|c|}{$\begin{array}{c}\text { Concentrado }{ }^{1} \\
\text { Concentrate }\end{array}$} \\
\hline & $\begin{array}{l}\text { Farelado com } \\
\text { farelo de soja } \\
\text { Grounded with } \\
\text { soybean meal }\end{array}$ & $\begin{array}{l}\text { Extrusado com } \\
\text { farelo de soja } \\
\text { Extruded with } \\
\text { soybean meal }\end{array}$ & $\begin{array}{l}\text { Farelado com } \\
\text { farelo de algodão } \\
\text { Grounded with } \\
\text { cottonseed meal }\end{array}$ & $\begin{array}{l}\text { Extrusado com } \\
\text { farelo de algodão } \\
\text { Extruded with } \\
\text { cottonseed meal }\end{array}$ \\
\hline \multicolumn{5}{|l|}{ Ingrediente (Ingredient) } \\
\hline Silagem de milho, \% (Corn silage) & 50,0 & 50,0 & 50,0 & 50,0 \\
\hline Farelo de soja, \% (Soybean meal) & 8,4 & 8,4 & - & - \\
\hline Farelo de algodão, \% (Cottonseed meal) & - & - & 10,8 & 10,8 \\
\hline Milho em grão, \% (Corn grain) & 41,6 & 41,6 & 39,2 & 39,2 \\
\hline Monensina sódica, g/animal/dia & & & & \\
\hline Sodium monensin, g/animal/day & 0,3 & 0,3 & 0,3 & 0,3 \\
\hline \multicolumn{5}{|l|}{$\begin{array}{l}\text { Composição bromatológica } \\
\text { Chemical compostion }\end{array}$} \\
\hline MS, \% (DM) & 39,3 & 39,5 & 39,2 & 39,3 \\
\hline $\mathrm{PB}, \% \mathrm{MS}(C P, \% D M)$ & 12,0 & 11,8 & 12,1 & 11,6 \\
\hline NDT, \% MS (TDN, \% DM) & 74,9 & 74,9 & 74,0 & 74,0 \\
\hline
\end{tabular}

damente $20 \%$, e de canhão dotado de bicos para entrada de água para resfriamento. Após a extrusão, os concentrados passaram por secador de fluxo de ar quente forçado e expostos ao sol para secagem final, até atingirem $90 \%$ de MS.

As dietas foram fornecidas na forma de ração completa, em uma única refeição diária às $8 \mathrm{~h}$. Duas vezes por semana foram feitos ajustes na quantidade fornecida de alimento para cada animal, de acordo com a pesagem das sobras, ofertando-se $10 \%$ a mais que o consumido no período anterior. Foram feitas amostragens periódicas e individuais das sobras retiradas, além do volumoso e dos concentrados oferecidos.

Os animais tiveram à disposição um núcleo mineral comercial, cujos níveis de garantia eram: P - 40 g; Ca 146 g; Na - 56 g; S - 40 g; Mg - 20 g; Cu - 350 mg; Zn 1.300 mg; Mn - 900 mg; Fe - 1050 mg; Co - 10 mg; I - 24 mg; Se - 10 mg; e F - 400 mg.

As análises referentes às composições médias das amostras, em teores de MS, PB, EE, FB, FDN e FDA, foram realizadas conforme AOAC (1995).

Foram realizadas pesagens dos animais no início e ao final do período experimental, além de pesagens intermediárias a cada 28 dias, sempre após jejum completo de 15 horas. Estimaram-se a área de olho-de-lombo entre a $12^{\mathrm{a}} \mathrm{e}$ a 13 a costelas (AOL) e a espessura de gordura de cobertura (EGC) sobre a $12^{\mathrm{a}}$ costela, a partir de imagens tomadas com ultra-som no início e no final do período experimental. Para isso, os animais foram contidos, submetidos à limpeza e à tosquia dos pêlos ( $1 \mathrm{~mm}$ ) no local de mensuração. O sítio de avaliação foi recoberto com camada delgada de óleo vegetal imediatamente antes da tomada das imagens.
Para a coleta dos dejetos, realizada semanalmente, as baias foram completamente limpas no dia anterior. Depois de colhidos, os dejetos foram homogeneizados para amostragem. As amostras foram imediatamente congeladas para análise posterior, segundo AOAC (1995), para caracterização individual, quantitativa e qualitativa, dos dejetos produzidos pelos animais e realização do balanço de nutrientes utilizando-se os valores de MS, PB, FDN e FDA, ingeridos e eliminados, segundo a fórmula:

quantidade do nutriente ingerido (kg) quantidade do nutriente nos dejetos $(\mathrm{kg})$

$\mathrm{BN} \%=$

quantidade do nutriente ingerido $(\mathrm{kg})$

Vale ressaltar que, como as fezes foram colhidas no chão, continham urina e pêlos dos animais.

Nas amostras de dejetos, também foram determinadas as quantidades dos seguintes macro e microminerais: $\mathrm{N}$, segundo metodologia descrita por Silva \& Queiroz (2002), e P, Ca, Mg, K, Na, Fe, Mn, Zn, Cu e Co, conforme relatado por Bataglia et al. (1983).

Quando os animais estavam com idade média de 420 dias, efetuou-se uma coleta extra de dejetos, que alimentaram 16 biodigestores, de modo que cada unidade representou um animal. Verificou-se a influência das fontes protéicas e do tratamento físico do concentrado sobre o desenvolvimento do processo, as produções potenciais de biogás e as reduções dos teores de sólidos voláteis (SV) e sólidos totais (ST).

Os biodigestores utilizados eram constituídos, basicamente, por três cilindros retos de PVC com diâmetros de 
200, 250 e $300 \mathrm{~mm}$ e altura de $500 \mathrm{~mm}$, acoplados sobre uma placa de PVC com $25 \mathrm{~mm}$ de espessura, caracterizados como biodigestores de bancada, com capacidade média individual de $12 \mathrm{~L}$ de substrato em fermentação. Os cilindros de 200 e $300 \mathrm{~mm}$ encontravam-se um dentro do outro, de modo que o espaço entre a parede externa do cilindro interior e a parede interna do cilindro exterior comportava um volume de água (selo de água). O cilindro de diâmetro intermediário tinha uma das extremidades vedadas, conservando apenas uma abertura para descarga do biogás, e estava emborcado no selo de água para propiciar condições anaeróbias e armazenar o gás produzido. Os biodigestores foram dispostos sobre uma bancada, em condições de temperatura ambiente, abrigados da luz solar e de chuvas.

Os teores de sólidos totais e sólidos voláteis foram verificados conforme metodologia descrita pela APHA (1995). Os abastecimentos foram feitos procurando-se obter substratos com $8 \%$ de sólidos totais, conforme expressões citadas por Lucas Jr. et al. (1993). Os biodigestores foram avaliados por todo o período em que apresentaram produções de biogás. Na Tabela 2 são apresentadas as quantidades médias utilizadas de água e dejetos nos biodigestores, para cada tratamento.

Os volumes de biogás produzidos diariamente foram determinados medindo-se o deslocamento vertical dos gasômetros e multiplicando-se pela área de sua seção transversal interna, de $0,0507 \mathrm{~m}^{2}$. Depois de cada leitura, os gasômetros foram zerados utilizando-se o registro de descarga do biogás. A correção do volume de biogás para as condições de $1 \mathrm{~atm}$ e $20^{\circ} \mathrm{C}$ foi feita conforme recomendações de Caetano (1985).

O potencial de produção de biogás foi calculado utilizando-se os dados de produção diária e as quantidades de dejetos in natura, de substrato, de sólidos totais e sólidos voláteis adicionados aos biodigestores, além das quantida- des de sólidos voláteis reduzidos durante o processo de biodigestão anaeróbia. Os valores foram expressos em $\mathrm{m}^{3} \mathrm{de}$ biogás/kg de substrato, de dejetos ou de sólidos totais e sólidos voláteis.

Todos os resultados foram analisados em um delineamento inteiramente ao acaso, com quatro tratamentos e quatro repetições por tratamento, e arranjo fatorial $2 \times 2$ (fonte protéica $\times$ tratamento físico do concentrado), com auxílio do SAS (1990) e as médias foram comparadas pelo teste Tukey. Probabilidade de até $6 \%$ foi aceita como significativa, desde que o coeficiente de variação tenha sido baixo.

\section{Resultados e Discussão}

Não houve interação significativa dos concentrados (Tabela 3) para nenhuma das características de desempenho avaliadas. Considerando o rendimento de carcaça de pelo menos $50 \%$, os animais de todos os tratamentos atingiram o peso mínimo de carcaça exigido pelo frigorífico (225 kg).

As fontes protéicas estudadas determinaram diferenças significativas para o ganho de peso (Tabela 3). O ganho médio diário dos animais alimentados com farelo de soja (1,55 kg/animal) e farelo de algodão (1,35 kg/animal) foram bons se considerada a relação volumoso:concentrado utilizada de 50:50.

Sampaio et al. (1998), utilizando animais 3/4 Canchim $\times$ $1 / 4$ Nelore, não encontraram diferença entre o farelo de soja e o farelo de algodão e obtiveram ganho de peso de $1,26 \mathrm{~kg} /$ animal/dia. Esses autores utilizaram maior proporção de volumoso, $60 \%$, o que pode explicar, em parte, os ganhos inferiores em comparação aos deste trabalho.

Silva et al. (1999) também não encontraram diferenças entre tratamentos na terminação de novilhos Pardo-suíço × Nelore e novilhos Nelore com média de 20 meses de idade. Os ganhos foram de 1,6; 1,4 e 1,2 kg/animal/dia quando

Tabela 2 - Quantidade média de dejetos, de água e teores de sólidos totais e sólidos voláteis no abastecimento de biodigestores Table 2 - Average amount of dejections, water and total and volatile solids concentration in the supplying of the biodigestors

\begin{tabular}{|c|c|c|c|c|c|c|}
\hline \multirow[t]{2}{*}{$\begin{array}{l}\text { Concentrado } \\
\text { Concentrate }\end{array}$} & \multicolumn{5}{|c|}{$\begin{array}{l}\text { Afluente } \\
\text { Afluent }\end{array}$} & \multirow[b]{2}{*}{$\begin{array}{c}\text { Sólidos voláteis }(\mathrm{kg}) \\
\text { Volatile solids }\end{array}$} \\
\hline & $\begin{array}{l}\text { Dejetos }(\mathrm{kg}) \\
\text { Dejections }\end{array}$ & $\begin{array}{l}\text { Água }(\mathrm{kg}) \\
\text { Water }\end{array}$ & $\begin{array}{l}\text { Sólidos totais }(\%) \\
\text { Total solids }\end{array}$ & $\begin{array}{l}\text { Sólidos totais }(\mathrm{kg}) \\
\text { Total solids }\end{array}$ & $\begin{array}{l}\text { Sólidos voláteis (\%) } \\
\text { Volatile solids }\end{array}$ & \\
\hline $\begin{array}{l}\text { Farelado com farelo de soja } \\
\text { Grounded with soybean meal }\end{array}$ & 5,09 & 7,54 & 8,76 & 1,11 & 8,05 & 1,02 \\
\hline $\begin{array}{l}\text { Extrusado com farelo de soja } \\
\text { Extruded with soybean meal }\end{array}$ & 5,63 & 6,99 & 8,43 & 1,06 & 7,73 & 0,98 \\
\hline $\begin{array}{l}\text { Farelado com farelo de algodão } \\
\text { Grounded with cottonseed meal }\end{array}$ & 4,37 & 8,63 & 7,48 & 0,97 & 6,80 & 0,88 \\
\hline $\begin{array}{l}\text { Extrusado com farelo de algodã } \\
\text { Extruded with cottonseed meal }\end{array}$ & ão 4,96 & 7,67 & 8,78 & 1,11 & 7,88 & 0,99 \\
\hline
\end{tabular}


incluíram farelo de soja, farelo de soja + uréia e uréia como fontes nitrogenadas, respectivamente. Coutinho Filho et al. (1995), no entanto, determinaram ganhos de peso diferentes com a inclusão do farelo de algodão e da uréia, com valores de 0,70 e $0,60 \mathrm{~kg} / \mathrm{animal} / \mathrm{dia}$, respectivamente, na dieta contendo cana-de-açúcar como volumoso.

Não foram observados efeitos do tratamento físico do concentrado sobre o ganho de peso dos animais. A extrusão, por envolver calor e pressão, afeta as frações protéicas e fibrosas dos alimentos, segundo Goelema \& Van Der Poel (1997). Esse tratamento é realizado visando à gelatinização das frações amiláceas, o que promove melhor aproveitamento dessas frações pelos animais. No entanto, temperaturas superiores a $100^{\circ} \mathrm{C}$, como as utilizadas durante a extrusão neste trabalho, podem desnaturar a proteína e/ou reagir com açúcares redutores, como glucose, galactose, frutose e especialmente a xilose nas reações de Maillard (Cleale et al., 1987, citados por Goelema \& Van Der Poel, 1997). Essas reações poderiam levar à redução na solubilidade da proteína e nas taxas de degradação ruminais. Em trabalho realizado por Gaebe et al. (1998), os ganhos nos animais alimentados com dietas extrusadas não foram superiores aos daqueles alimentados com concentrados farelados, provavelmente porque os consumos não aumentaram com o processamento por extrusão.

Não houve efeitos da fonte protéica ou do tipo de processamento do concentrado sobre a ingestão diária de MS e de PB. O mesmo foi observado por Orias et al. (2002), que avaliou a soja em grão extrusada e seus efeitos na digestão protéica para novilhos holandeses em terminação e observaram valores médios de ingestão de MS de 9,60 kg/ animal/dia. Esses autores concluíram que a extrusão do grão de soja a temperaturas de até $138^{\circ} \mathrm{C}$ não foi suficiente para proteger as proteínas da digestão ruminal e maximizar a utilização pós-ruminal de aminoácidos. Gaebe et al. (1998), por sua vez, avaliaram a terminação de bovinos cruzados Angus $\times$ Gelbivieh alimentados com concentrados contendo grãos de milho e sorgo e observaram que a extrusão reduziu a ingestão diária de MS e o ganho de peso, em relação aos grãos quebrados, mas não alterou a eficiência alimentar. Assim, os resultados experimentais avaliando a extrusão do concentrado ou de ingredientes do concentrado não têm mostrado efeitos benéficos no desempenho de bovinos. Talvez sejam necessários estudos mais detalhados do processamento.

Neste trabalho, houve diferença entre as fontes protéicas para a conversão alimentar: 4,73 e 5,31 kg de MS ingerida/kg de ganho de peso, respectivamente, para farelo de soja e de algodão, considerando os valores médios entre os tratamentos físicos. Sampaio et al. (1998) obtiveram 7,23 kg de MS ingerida/ kg de ganho para animais Canchim-Nelore alimentados com concentrados contendo farelo de soja ou de algodão. Apesar de a conversão ter sido pior, esses autores utilizaram proporção mais elevada de volumoso, $60 \%$.

Coutinho Filho et al. (1995) avaliaram dietas contendo farelo de algodão para acabamento de novilhos Nelore

Tabela 3 - Pesos inicial (PI) e final (PF), ganho diário de peso corporal (GPC), ingestão diária de matéria seca (IMS), conversão alimentar (CA), ingestão diária de proteína bruta (IPB), eficiência protéica (EP), áreas de olho de lombo inicial (AOLin) e final (AOLfi) e espessuras de gordura de cobertura inicial (EGin) e final (EGCfi) dos animais em função dos tratamentos, e probabilidade dos fatores fonte protéica (FP), processamento do concentrado (PC) e interação (I)

Table 3 - Initial (PI) and final (PF) weight, daily body weight gain (GPC), daily dry matter intake (IMS), feed convertion (CA), daily crude protein intake (IPB), protein efficiency (EP), initial (AOLin) and final (AOLfi) ribeye area and initial (EGin) and final (EGfi) backfat thickness of animals by treatment, and probabilities of the factors protein source (FP), physical concentrate process (PC) and interaction (I)

\begin{tabular}{|c|c|c|c|c|c|c|c|c|}
\hline \multirow[t]{2}{*}{$\begin{array}{l}\text { Variável } \\
\text { Variable }\end{array}$} & \multicolumn{4}{|c|}{$\begin{array}{c}\text { Tratamento }^{1} \\
\text { Treatment }\end{array}$} & \multicolumn{3}{|c|}{$\begin{array}{c}\text { Probabilidade } \\
\text { Probability }\end{array}$} & \multirow[t]{2}{*}{$\mathrm{CV}^{2}(\%)$} \\
\hline & SF & $\mathrm{SE}$ & $\mathrm{AF}$ & $\mathrm{AE}$ & FP & $\mathrm{PC}$ & I & \\
\hline $\mathrm{PF}, \mathrm{kg}$ & 489,80 & 484,50 & 460,70 & 474,80 & 0,313 & 0,816 & 0,611 & 7,71 \\
\hline GPC, kg/animal & 1,64 & 1,46 & 1,35 & 1,35 & 0,057 & 0,334 & 0,386 & 12,85 \\
\hline IMS, kg/animal & 7,76 & 6,83 & 7,47 & 6,90 & 0,827 & 0,182 & 0,736 & 14,82 \\
\hline IPB, kg/animal & 0,94 & 0,81 & 0,90 & 0,81 & 0,773 & 0,118 & 0,841 & 14,79 \\
\hline EP, kg GPC/kg IPB & 1,77 & 1,79 & 1,51 & 1,66 & 0,021 & 0,244 & 0,399 & 8,50 \\
\hline AOLin, $\mathrm{cm}^{2}$ & 51,67 & 54,83 & 44,67 & 54,59 & 0,441 & 0,082 & 0,493 & 10,18 \\
\hline AOLfi, $\mathrm{cm}^{2}$ & 71,91 & 73,54 & 70,55 & 70,79 & 0,441 & 0,723 & 0,792 & 7,19 \\
\hline EGCin, mm & 2,82 & 3,25 & 2,99 & 2,57 & 0,395 & 0,990 & 0,176 & 20,18 \\
\hline EGCfi, mm & 3,49 & 3,83 & 3,48 & 3,49 & 0,393 & 0,393 & 0,420 & 10,82 \\
\hline
\end{tabular}

${ }^{1} \mathrm{SF}$ - concentrado farelado com farelo de soja (grounded concentrate with soybean meal); SE - concentrado extrusado com farelo de soja (extrused concentrate with soybean meal); AF - concentrado farelado com farelo de algodão (grounded concentrate with cottonseed meal); AE - concentrado extrusado com farelo de algodão (extrused concentrate with cottonseed meal).

${ }^{2} \mathrm{CV}$ - coeficiente de variação (coefficient of variation). 
com idade média de 30 meses e encontraram valores elevados de conversão alimentar (10,3 kg de MS ingerida/kg de ganho de peso). Provavelmente esses resultados estejam associados à idade dos animais e à baixa qualidade do volumoso utilizado.

A fonte protéica também afetou significativamente a eficiência protéica. $\mathrm{O}$ farelo de soja foi superior ao farelo de algodão e proporcionou médias de 1,78 e 1,59 kg de ganho de peso/kg de PB ingerida, respectivamente, considerando os valores médios entre os tratamentos físicos. As fontes protéicas estudadas não afetaram a ingestão de alimentos, mas o farelo de soja determinou melhor aproveitamento da fração protéica, que, por sua vez, favoreceu o aumento do ganho de peso e a conversão alimentar. Observou-se maior capacidade do farelo de soja em fornecer proteína digestível em comparação ao farelo de algodão (Van Soest, 1994).

Os resultados de AOL e EGC não diferiram entre os concentrados, o que é justificável, uma vez que todos os animais eram de mesma raça e não apresentaram diferença no peso final. Gaebe et al. (1998) observaram que a extrusão do milho e do sorgo reduziu significativamente a AOL, mas não a EGC, quando compôs $78,6 \%$ da dieta de novilhos cruzados em terminação, em comparação às dietas em que esses ingredientes apenas sofreram processamento mecânico. Esses autores atribuíram a menor AOL ao menor peso de abate dos animais, uma vez que os animais que receberam grãos extrusados estavam em acidose subclínica e reduziram o ganho de peso no decorrer do confinamento.

Quanto menos acabado o animal, representado pelos valores iniciais, maior a variabilidade da estimativa da AOL e da EGC com o uso do ultra-som. Se há maior deposição de gordura, esta técnica é mais precisa. Os concentrados testados nesse trabalho resultaram em EGC superior ao mínimo exigido pelos frigoríficos (3 mm de gordura sobre o contrafilé), considerando a idade dos animais (16 meses ao final do experimento) e a raça (Canchim), que é tardia na deposição de gordura.

Não houve influência dos fatores de variação ou de sua interação sobre o balanço da MS (Tabela 4), que apresentou valores próximos aos de digestibilidade da MS, de 65,4\%, observados por Leão et al. (2004), para rações fareladas e níveis de consumo semelhantes aos deste estudo.

Apesar de ser uma estimativa mais grosseira do aproveitamento de cada fração nutritiva, é possível verificar interação significativa entre fonte protéica e tratamento físico do concentrado para o balanço da PB. Quando o concentrado foi extrusado, a PB foi melhor aproveitada pelo animal alimentado com o concentrado contendo farelo de soja em comparação àqueles que ingeriram farelo de algodão, no entanto, essa diferença não foi significativa para o concentrado farelado, ou seja, a extrusão do concentrado se justificaria caso o farelo de soja fosse o composto protéico, mas não se utilizado o farelo de algodão.

Os valores do balanço da PB obtidos foram inferiores aos encontrados na literatura, mas podem ter sido influenciados pelos teores de nitrogênio na urina e nos pêlos dos animais, incorporados aos dejetos. Entretanto, esses resultados foram semelhantes aos descritos por Sampaio et al. (2000), que verificaram coeficientes de digestibilidade da PB de 50,4; 46,4 e 60,9\%, respectivamente, para rações com farelo de algodão, levedura e uréia.

O balanço da FDN não diferiu entre os concentrados para todos os fatores estudados e suas interações. No entanto, houve influência do tratamento físico sobre o balanço da FDA, com médias de 50,1 e 42,6\% para as rações farelada e extrusada, respectivamente, considerando os valores médios entre as fontes protéicas, o que pode estar associado à menor quantidade de FDA digestível nos concentrados extrusados. Bertipaglia (2002), trabalhando

Tabela 4 - Balanço de nutrientes, em porcentagem, da matéria seca (MS), proteína bruta (PB), fibra em detergente neutro (FDN) e fibra em detergente ácido (FDA) nos animais em função dos tratamentos, e probabilidade dos fatores fonte protéica (FP), processamento do concentrado (PC) e interação (I)

Table 4 - Nutrient balance, in percentage, of dry matter (MS), crude protein (PB), neutral detergent fiber (FDN) and acid detergent fiber (FDA) of animals by treatment, and probabilities of the factors protein source (FP), physical concentrate process $(P C)$ and interaction (I)

\begin{tabular}{|c|c|c|c|c|c|c|c|c|}
\hline \multirow[t]{2}{*}{$\begin{array}{l}\text { Balanço do nutriente } \\
\text { Nutrient balance }\end{array}$} & \multicolumn{4}{|c|}{$\begin{array}{c}\text { Tratamento }^{1} \\
\text { Treatment }\end{array}$} & \multicolumn{3}{|c|}{$\begin{array}{c}\text { Probabilidade } \\
\text { Probability }\end{array}$} & \multirow[t]{2}{*}{$\mathrm{CV}^{2}(\%)$} \\
\hline & SF & SE & $\mathrm{AF}$ & $\mathrm{AE}$ & FP & PC & I & \\
\hline PB & 55,1 & 61,5 & 53,1 & 52,5 & 0,006 & 0,104 & 0,053 & 5,90 \\
\hline FDN & 47,4 & 43,3 & 45,8 & 38,5 & 0,351 & 0,109 & 0,627 & 15,04 \\
\hline FDA & 51,3 & 45,2 & 49,0 & 40,0 & 0,270 & 0,039 & 0,654 & 14,04 \\
\hline
\end{tabular}

${ }^{1} \mathrm{SF}$ - concentrado farelado com farelo de soja (grounded concentrate with soybean meal); SE - concentrado extrusado com farelo de soja (extrused concentrate with soybean meal); AF - concentrado farelado com farelo de algodão (grounded concentrate with cottonseed meal); AE - concentrado extrusado com farelo de algodão (extrused concentrate with cottonseed meal).

${ }^{2} \mathrm{CV}$ - coeficiente de variação (coefficient of variation) 
Tabela 5 - Teores de macro ( $\mathrm{g} / 100 \mathrm{~g}$ de MS) e de micro minerais ( $\mathrm{mg} / 100 \mathrm{~g}$ de MS) dos dejetos de animais em terminação em função dos tratamentos, e probabilidade dos fatores fonte protéica (FP), processamento do concentrado (PC) e interação (I)

Table 5 - Macro $(\mathrm{g} / 100 \mathrm{~g}$ of DM) and micro ( $\mathrm{mg} / 100 \mathrm{~g}$ of DM) mineral concentration of dejections of finishing animals by treatments, and probabilities of the factors protein source (FP), physical concentrate process (PC) and interaction (I)

\begin{tabular}{|c|c|c|c|c|c|c|c|c|}
\hline \multirow[t]{2}{*}{ Mineral } & \multicolumn{4}{|c|}{$\begin{array}{c}\text { Tratamento }^{1} \\
\text { Treatment }\end{array}$} & \multicolumn{3}{|c|}{$\begin{array}{c}\text { Probabilidade } \\
\text { Probability }\end{array}$} & \multirow[t]{2}{*}{$\mathrm{CV}^{2}(\%)$} \\
\hline & SF & SE & $\mathrm{AF}$ & $\mathrm{AE}$ & FP & PC & I & \\
\hline
\end{tabular}

Macro

\begin{tabular}{lrrrrrrrr}
$\mathrm{N}$ & 2,27 & 2,12 & 2,27 & 2,26 & 0,191 & 0,127 & 0,202 & 4,45 \\
$\mathrm{P}$ & 0,90 & 0,94 & 1,03 & 1,05 & 0,001 & 0,349 & 0,682 & 5,17 \\
$\mathrm{Ca}$ & 0,40 & 0,43 & 0,38 & 0,44 & 0,863 & 0,012 & 0,359 & 6,86 \\
$\mathrm{Mg}$ & 0,54 & 0,55 & 0,56 & 0,62 & 0,038 & 0,181 & 0,208 & 6,93 \\
$\mathrm{~K}$ & 1,57 & 1,44 & 1,40 & 1,62 & 0,953 & 0,575 & 0,063 & 11,24 \\
$\mathrm{Na}$ & 0,40 & 0,43 & 0,37 & 0,42 & 0,339 & 0,113 & 0,743 & 11,61 \\
\hline Micro & & & & & & & \\
$\mathrm{Fe}$ & 114,50 & 136,13 & 113,44 & 117,95 & 0,462 & 0,322 & 0,512 & 21,02 \\
$\mathrm{Mn}$ & 12,96 & 13,76 & 12,39 & 12,89 & 0,084 & 0,115 & 0,718 \\
$\mathrm{Zn}$ & 15,27 & 15,16 & 14,84 & 15,46 & 0,883 & 0,571 & 0,414 & 5,87 \\
$\mathrm{Cu}$ & 3,33 & 3,34 & 3,07 & 3,20 & 0,060 & 0,473 & 0,517 & 5,95 \\
$\mathrm{Co}$ & 8,85 & 8,92 & 8,90 & 8,95 & 0,544 & 0,362 & 0,885 & 1,45 \\
\hline
\end{tabular}

${ }^{1} \mathrm{SF}$ - concentrado farelado com farelo de soja (grounded concentrate with soybean meal); SE - concentrado extrusado com farelo de soja (extrused concentrate with soybean meal); AF - concentrado farelado com farelo de algodão (grounded concentrate with cottonseed meal); AE - concentrado extrusado com farelo de algodão (extrused concentrate with cottonseed meal).

${ }^{2} \mathrm{CV}$ - coeficiente de variação (coefficient of variation).

com concentrados contendo milho e soja grão, observou que a solubilização da celulose é alterada pelo processo de extrusão com diminuição dos valores de FDA.

Houve efeito da fonte protéica sobre os teores de P e Mg e do tipo de processamento do concentrado sobre o teor de Ca (Tabela 5). Os teores de Ca foram 0,39 e 0,43 g/100 g de MS, respectivamente, para os tratamentos com concentrado farelado e extrusado, considerando os valores médios entre as fontes protéicas. Nenhuma das interações apresentadas nesta tabela foi significativa.

Os valores de minerais encontrados foram similares aos obtidos por autores que trabalharam com dejetos de bovinos: 2,05; 1,44 e 1,49\% de N, P, K, respectivamente, (Hoptgartner, citado por Amorim, 2002) e, ainda, 1,80 a 3,70\% de N, 0,42 a 1,03\% de P e 0,61 a 2,50\% de K (Kiehl, 1985). Por outro lado, as concentrações de $\mathrm{Na}$ obtidas nos dejetos dos animais deste experimento foram mais elevadas que aquelas encontradas nos dejetos de caprinos recebendo dietas com 60 e $40 \%$ de volumoso (Amorim, 2005), mas os teores de microminerais foram inferiores. Os valores encontrados por Amorim (2005) foram, em média, por $100 \mathrm{~g}$ de MS: 0,17 g de Na; 165 mg de Fe; 26 mg de Zn; 30 mg de Mn; e 5,3 mg de Cu.

A fonte protéica e sua interação com o tipo de processamento do concentrado não alteraram os resultados para redução de sólidos totais (RST) e redução de sólidos voláteis (RSV) (Tabela 6). Por outro lado, o tipo de processamento do concentrado afetou significativamente estas variáveis, com médias de 27,76 e 37,69\% para RST, e
30,37 e 41,92\% para RSV, respectivamente, para os concentrados farelados e extrusados, considerando os valores médios entre as fontes protéicas.

De acordo com Amorim (2005), a menor redução de sólidos pode estar associada aos conteúdos de FDA e, principalmente, de lignina nos substratos, uma vez que a presença destas frações em maiores quantidades compromete a degradação dos substratos. Neste trabalho, a extrusão pode ter alterado a relação dos componentes da FDA em comparação ao tratamento com concentrado farelado, causando maior redução de ST e SV. De qualquer modo, as fezes dos animais alimentados com concentrados extrusados provavelmente constituíram substratos mais assimiláveis durante a biodigestão anaeróbia, contribuindo inclusive com maiores quantidades de nutrientes disponíveis neste meio e proporcionando melhores condições para o desenvolvimento da população de microrganismos anaeróbios, o que pode ter facilitado a redução de material orgânico e a produção de biogás.

A produção de biogás até o $70^{0}$ dia foi muito pequena (Figura 1) e manteve-se praticamente irrisória, correspondendo a aproximadamente $5 \%$ do total. A partir deste período, houve volume maior de produção de biogás, com altas produções até aproximadamente o 200 으 dia. Esse comportamento da produção de biogás provavelmente está relacionado à utilização do ionóforo nos concentrados experimentais, que é usado na alimentação de ruminantes com o objetivo de aumentar a eficiência ruminal, inibindo 
Tabela 6 - Redução percentual de sólidos totais (RST) e sólidos voláteis (RSV) nos dejetos de animais em terminação, em função dos tratamentos, após tratamento em biodigestor anaeróbio, e probabilidade dos fatores fonte protéica (FP), processamento do concentrado (PC) e interação (I)

Table 6 - Percent reduction of total (RST) and volatiles (RSV) solids on dejections of finishing animals by treatments, after anaerobic biodigestor treatment, and probabilities of the factors protein source (FP), physical concentrate process (PC) and interaction (I)

\begin{tabular}{|c|c|c|c|c|c|c|c|c|}
\hline \multirow[t]{2}{*}{$\begin{array}{l}\text { Variável } \\
\text { Variable }\end{array}$} & \multicolumn{4}{|c|}{$\begin{array}{c}\text { Tratamento }^{1} \\
\text { Treatment }\end{array}$} & \multicolumn{3}{|c|}{$\begin{array}{c}\text { Probabilidade } \\
\text { Probability }\end{array}$} & \multirow[t]{2}{*}{$\mathrm{CV}^{2}(\%)$} \\
\hline & SF & SE & $\mathrm{AF}$ & $\mathrm{AE}$ & FP & PC & I & \\
\hline RST & 28,49 & 38,91 & 27,03 & 36,48 & 0,608 & 0,020 & 0,898 & 22,56 \\
\hline RSV & 30,60 & 43,20 & 30,14 & 40,65 & 0,699 & 0,010 & 0,788 & 20,98 \\
\hline
\end{tabular}

${ }^{1} \mathrm{SF}$ - concentrado farelado com farelo de soja (grounded concentrate with soybean meal); SE - concentrado extrusado com farelo de soja (extrused concentrate with soybean meal); AF - concentrado farelado com farelo de algodão (grounded concentrate with cottonseed meal); AE - concentrado extrusado com farelo de algodão (extrused concentrate with cottonseed meal).

$2 \mathrm{CV}$ - coeficiente de variação (coefficient of variation).

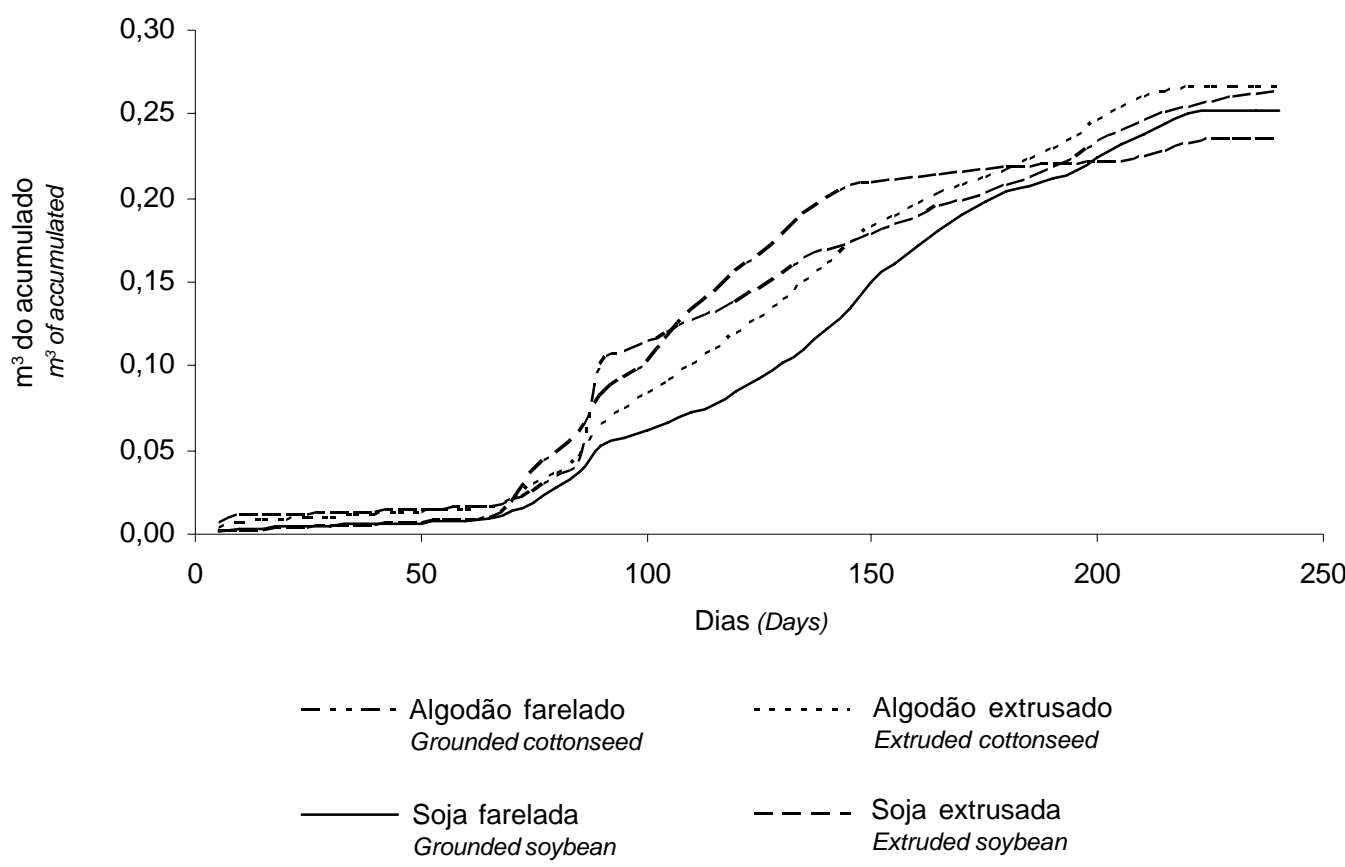

Figura 1 - Produção acumulada de biogás $\left(\mathrm{m}^{3}\right)$ a partir de dejetos de animais em terminação em confinamento alimentados com dietas com concentrado farelado ou extrusado formulado com diferentes fontes protéicas.

Figure 1 - Accumulated biogas production $\left(m^{3}\right)$ from dejections of feedlot animals fed diets with grounded or extruded concentrate formulated with different formulated with different protein sources.

a ação das bactérias gram positivas produtoras de acetato e selecionando as gram negativas, produtoras de propionato (Russel \& Strobel, 1989). Assim, a utilização deste ionóforo diminui a relação acetato:propionato, como observado por Vargas et al. (2001), e reduz também a produção de metano, uma vez que diminuiu a disponibilidade de hidrogênio e carbono, substratos para as bactérias metanogênicas, em decorrência da maior produção de propionato (3C) em relação à produção de acetato (2C).

Ressalta-se que somente 40 a $50 \%$ do ionóforo monensina é absorvido e que esta fração é rapidamente metabolizada pelo organismo e excretada pela bílis. Além disso, é uma substância estável nos fluidos ruminal, abomasal e nas fezes (Donoho et al., 1978). Então, os efeitos da monensina são semelhantes aos desencadeados no ambiente ruminal. Donoho (1984) observou que as concentrações de monensina existentes nas fezes declinaram de 4,5 para 2,6 ppm depois de 70 dias de incubação. Isso explica a demora no início da produção de biogás, pois, nos primeiros 70 dias, a ação da monensina impediu o crescimento da população de bactérias produtoras de acetato, diminuindo a disponibilidade de carbono e hidrogênio para as bactérias metanogênicas, que, mesmo não sofrendo ação direta da monensina por serem gram negativas, também tiveram seu crescimento populacional afetado pela falta de substrato.

Estimando-se a produção de biogás por quilograma de dejetos neste trabalho (Tabela 2; Figura 1), foram obtidos valores acima do preconizado por Rachamandra et al. 
(2004), que estimaram de 0,036 a $0,042 \mathrm{~m}^{3} / \mathrm{kg}$ de esterco, quantidade suficiente para atender à demanda diária de biogás por habitante da zona rural.

Em confinamentos comerciais que duram aproximadamente 100 dias, caso os dejetos fossem utilizados para produção de energia, apenas pequena parte da produção de metano ocorreria ao ar livre e a maior parte ocorreria no interior do biodigestor, onde é possível capturar o gás produzido. Incluindo-se biodigestores no sistema, poderia haver a produção e o aproveitamento de energia, e o impacto ambiental também seria diminuído, pois a combustão do metano resulta em gás carbônico, que contribui 30 vezes menos para o efeito estufa que o metano (Johnson et al., 1991).

\section{Conclusões}

Como componente protéico da dieta de tourinhos jovens confinados, o farelo de soja foi melhor que o farelo de algodão. Quanto ao ambiente, os dejetos produzidos pelos animais alimentados com uma ou outra fonte protéica causaram o mesmo tipo de impacto.

A extrusão como tratamento físico do concentrado não trouxe benefícios ao desempenho de bovinos jovens terminados em confinamento, mas contribuiu favoravelmente para a produção de biogás por disponibilizar maior quantidade de substrato para os microrganismos anaeróbios.

A utilização de ionóforos na dieta de animais em confinamento retardou o início da produção de biogás e alterou sua produção total.

\section{Literatura Citada}

AL-MASRI, M.R. Changes in biogas production due different ratios of some animal and agricultural wastes. Bioresource Technology, v.77, n.1, p.97-100, 2001.

AMORIM, A.C. Caracterização dos dejetos de caprinos: reciclagem energética e de nutrientes. Jaboticabal: Universidade Estadual Paulista, 2002. 108p. Dissertação (Mestrado em Produção Animal) - Universidade Estadual Paulista, 2002.

AMORIM, A.C. Avaliação do potencial de impacto ambiental e do uso da compostagem e biodigestão anaeróbia na produção de caprinos. Jaboticabal: Universidade Estadual Paulista, 2005. 129p. Tese (Doutorado em Zootecnia) Universidade Estadual Paulista, 2005.

ANUALPEC. Anuário da pecuária brasileira. São Paulo: FNP Consultoria, 2003. 400p

ASSOCIATION OF OFFICIAL AGRICULTURE CHEMISTS AOAC. Official methods of analysis. 16.ed. Arlington: Patricial Cunnif, 1995. 1025p.

AMERICAN PUBLIC HEALTH ASSOCIATION - APHA. Standard methods for examination of water and waste water. 19.ed. Washington: American Water Works Association, 1995. 1134p.

BATAGLIA, O.G.; FURLANI, A.M.C.; TEIXEIRA, J.P.F. et. al. Métodos de análises químicas de plantas. Campinas: Instituto Agronômico, 1983. 48p. (Boletim Técnico).
BERTIPAGLIA, L.M.A. Avaliação dos efeitos das temperaturas de extrusão em misturas de soja integral e milho. Jaboticabal: Universidade Estadual Paulista, 2002. 134p. Dissertação (Mestrado em Zootecnia) - Universidade Estadual Paulista, 2002

COMPANHIA AUXILIAR DE EMPRESAS ELÉTRICAS BRASILEIRAS - CAEEB. O biogás e sua tecnologia. Rio de Janeiro: Departamento de Fontes Alternativas de Energia, 1981. $31 \mathrm{p}$.

CAETANO, L. Proposição de um sistema modificado para quantificação de biogás. Botucatu: Universidade Estadual Paulista, 1985. 75p. Dissertação (Mestrado em Energia na Agricultura) - Universidade Estadual Paulista, 1985.

CAMIRE, M.E. Protein functionality modification by extrusion cooking. Journal of the American Oil Chemists' Society, v.68, n.2, p.200-205, 1991.

COUTINHO FILHO, J.L.V.; SAMPAIO, A.A.M.; EZEQUIEL, J.M.B. et al. Efeito de fontes de nitrogênio e da cobertura do cocho sobre o desemepnho de bovinos confinados. Revista da Sociedade Brasileira de Zootecnia, v.24, n.3, p.363-370, 1995.

DONOHO, A.L. Biochemical studies on the fate of monensin in animals and in the environment. Journal of Animal Science, v.58, n.6, p.1528-1539, 1984.

DONOHO, A.; MANTHEY, J.; OCCOLOWITZ, J. et al. Metabolism of monensin in the steer and rat. Journal of Agricultural and Food Chemistry, v.26, n.6, p.1090-1096, 1978.

GAEBE, J.R.; SANSON, D.W.; RUSH, I.G. et al. Effects of extruded corn or grain sorghun on intake, digestibility, weight gain, and carcasses of finishing steers. Journal of Animal Science, v.76, n.8, p.2001-2007, 1998.

GOELEMA, J.O.; VAN DER POEL, A.F.B. Nutritional effects of expander processing for ruminants. In: Van der POEL, A.F.B. (Ed.) Expander processing of animal feeds. Wagenigen: Ponsen \& Looijen, 1997. p.59-71.

GÜNGÖR-DEMIRCI, G.; DEMIRER, G.N. Effect of initial COD concentration, nutrient addition, temperature and microbial acclimation on anaerobic treatability of broiler and cattle manure. Bioresource Technology, v.93, n.2, p.109-117, 2004.

HAYTHORNTHWAITE, A. Extrusion: as a toll for improved nutritional vallue of feeds. Reading: Creative Press, 1986. 4p.

JOHNSON, D.E.; HILL, T.M.; CARMEAN, B.R. et al. New perspectives on ruminant methane emissions. In: WENK, C.; BOESSINGER, M. (Eds.). Energy metabolism of farm animals. Zurique: Institut für Nutztierwissenschaften, Gruppe Ernährung, 1991. 376p. (EAAP publication, 58).

KELLEHER, B.P.; LEAHY, J.J.; HENIHAN, A.M. et al. Advances in poultry litter disposal technology - a review. Bioresource Technology, v.83, n.1, p.27-36, 2002.

KIEHL, E.J. Fertilizantes orgânicos. São Paulo: Agronômica Ceres, 1985. 492p.

LANNA, D.P.D.; BARIONI, L.G.; TEDESCHI, L.O. et al. RLM 2.0: ração de lucro máximo. Versão 2.0. Piracicaba: Escola Superior de Agricultura Luiz de Queiroz, 1999. (CD-ROM).

LEÃO, M.I.; VALADARES FILHO, S.C.; RENNÓ, L.N. et al. Consumo e digestibilidade totais e parciais de matéria seca, matéria orgânica, proteína bruta e extrato etéreo em novilhos submetidos a três níveis de ingestão e duas metodologias de coleta de digestas abomasal e omasal. Revista Brasileira de Zootecnia, v.33, n.6, p.1604-1615, 2004.

LUCAS JR., J.; ORTOLANI, A.F.; BENINCASA, M. et al. Avaliação do uso de inoculo no desempenho de biodigestores abastecidos com dejeto de frangos de corte com cama de maravalha. In: CONGRESSO BRASILEIRO DE ENGENHARIA AGRÍCOLA, 22., 1993, Ilhéus. Anais... Ilhéus: Sociedade Brasileira de Engenharia Agrícola, 1993. v.2, p.915-930.

MINAMI, K.; TANAKA, K. Atmospheric methane: sources, sinks and strategies for reducing agricultural emission. Water Science Technology, v.36, n.6-7, p.509-516, 1997. 
NICHOLSON, F.A.; CHAMBERS, B.J.; WILLIAMS, J.R. et al. Heavy metal contents of livestock feeds and animal manures in England and Wales. Bioresource Technology, v.70, n.1, p.23-31, 1999.

O’CONNOR, C. Product development services available from extruder manufactures. In: O'CONNOR, C. (Ed.) Extrusion technology for the food industry. New York: Elsevier Applied Science, 1987. p.71-75.

ORIAS, F.; ALDRICH, C.G.; ELIZALDE, J.C. et al. The effects of dry extrusion of whole soybean on digestion of protein and amino acids by steers. Journal of Animal Science, v.80, n.9, p.2493-2501, 2002.

RAMACHANDRA, T.V.; KAMAKSHI, G.; SHRUTHI, B.V. Bioresource status in Karnataka. Renewable and Sustainable Energy Review's, v.8, n.1, p.1-47, 2004.

RUSSEL, J.B.; STROBEL, H.J. Effect of ionophores on ruminal fermentation. Applied Environmental Microbiology, v.55, n.1, p.1-6, 1989 .

SAMPAIO, A.A.M.; BRITO, R.M.; VIEIRA, P.F. et al. Efeito da suplementação protéica sobre crescimento, terminação e viabilidade econômica de bezerros mestiços Canchim confinados pós-desmama. Revista Brasileira de Zootecnia, v.27, n.4, p.823-831, 1998.

SAMPAIO, A.A.M.; VIEIRA, P.F.; BRITO, R.M. Digestão total e parcial de nutrientes em bovinos alimentados com rações contendo levedura, uréia ou farelo de algodão. Revista Brasileira de Zootecnia, v.29, n.2, p.589-597, 2000.
STATISTICAL ANALYSIS SYSTEM - SAS. SAS user's guide: statistics. Cary: 1990. 956p.

SILVA, D.J.; QUEIROZ, A.C. Análise de alimentos: métodos químicos e biológicos. 2.ed. Viçosa, MG: Editora UFV, 2002. 178p.

SILVA, J.M.; FEIJÓ, G.L.D.; THIAGO L.R.L.S. et al. Desempenho animal e avaliação do potencial produtivo de forragens para ensilagem, por intermédio de diferentes fontes de suplementação nitrogenada. Revista Brasileira de Zootecnia, v.28, n.3, p.642-653, 1999.

TEIXEIRA, I.A.M.A. Métodos de estimativa de composição corporal e exigências nutricionais de cabritos $F 1$ (Boer $x$ Saanen). Jaboticabal: Universidade Estadual Paulista, 2004. 92p. Tese (Doutorado em Produção Animal) - Universidade Estadual Paulista, 2004.

Van SOEST, P.J. Nutritional ecology of the ruminants. 2.ed. Ithaca: Cornell University Press, 1994. 476p.

VARGAS, L.H.; LANA, R.P.; MÂNCIO, A.B. et al. Influência de Rumensin ${ }^{\circledR}$, óleo de soja e níveis de concentrado sobre o consumo e os parâmetros fermentativos ruminais em bovinos. Revista Brasileira de Zootecnia, v.30, n.5, p.1650-1658, 2001. 